\title{
Nanoindentation deformation and cracking in sapphire
}

\author{
V. Trabadelo ${ }^{a^{*}}$, S. Pathak ${ }^{\mathrm{b}}$, F. Saeidi ${ }^{\mathrm{c}}$, M. Parlinska-Wojtan ${ }^{\mathrm{d}}$, K. Wasmer ${ }^{\mathrm{c}}$ \\ ${ }^{a}$ Mohammed VI Polytechnic University, Materials Science and Nano-engineering Department, lot 660, \\ Hay Moulay Rachid, 43150 Ben Guerir, Morocco \\ ${ }^{\mathrm{b}}$ University of Nevada Reno, Chemical and Materials Engineering Department, Reno, Nevada, USA \\ ${ }^{c}$ Empa, Swiss Federal Laboratories for Materials Science and Technology, Advanced Materials \\ Processing, Feuerwerkerstrasse 39, CH-3602 Thun, Switzerland \\ ${ }^{\mathrm{d}}$ Institute of Nuclear Physics, Polish Academy of Sciences, PL-31342 Krakow, Poland
}

\begin{abstract}
:
Single crystal sapphire is an anisotropic material and its mechanical behaviour depends on the crystallographic orientation. In this work, a systematic study is performed to investigate the effect of crystallographic orientation on the deformation and cracking of sapphire by means of nanoindentation using spherical indenters. It aims also at determining the physical origin of the "pop-in" appearing in the nanoindentation curves. For that purpose, nanoindentations were performed where the load was increased until the detection of the "pop-in", followed by direct unloading. After SEM and TEM observation of the indents, it is concluded that the deformation mechanisms of sapphire depend on the tip radius and the applied indentation stress: exclusively twin formation for the smaller 1 and $2 \mu \mathrm{m}$ tip radii indenters and twin formation together with crack propagation for larger $10 \mu \mathrm{m}$ tip radius spherical indenter. It was also determined that
\end{abstract}

\footnotetext{
* Corresponding author: Vera Trabadelo; Mohammed VI Polytechnic University, Materials Science and Nano-engineering department, lot 660, Hay Moulay Rachid, 43150 Ben Guerir, Morocco
} Tel: +212 5250730 22; E-mail: vera.trabadelo@um6p.ma

This document is the accepted manuscript version of the following article: Trabadelo, V., Pathak, S., Saeidi, F., Parlinska-Wojtan, M., \& Wasmer, K. (2019). Nanoindentation deformation and cracking in sapphire. Ceramics Internationa1, 45(8), 9835-9845. 
the cracks propagate preferentially in the $\left(101 ;^{-} 2\right)$ " $R$-plane". Therefore, this study is supplement to and enrichment of existing studies on deformation and cracking behavior of sapphire under spherical nanoindentation.

Keywords: $\mathrm{Al}_{2} \mathrm{O}_{3}$, D.; plasticity, C.; fracture, C.; spherical nanoindentation

\section{INTRODUCTION}

Sapphire $\left(\mathrm{Al}_{2} \mathrm{O}_{3}\right)$ is the third hardest mineral material (after diamond and moissanite) and therefore, it is used in many industrial fields such as the fabrication of windows glasses, missiles domes or transparent armors [1]. Additionally, its combination of excellent chemical, electrical, mechanical, optical, thermal and durability properties makes sapphire to be the preferred material for the manufacturing of high performance systems and components. However, its brittleness and hardness make the machining of sapphire very challenging and therefore it is carried out most often by grinding $[2,3]$ or laser machining $[4,5]$. Consequently, it is of key importance to understand the fracture and material removal mechanisms of sapphire at different scales in order to be able to optimize the processing parameters. Recently, Wasmer et al. performed a parametric experimental study of sapphire grinding via a design of experiments approach that allowed finding a set of optimum grinding parameters for single crystal sapphire [2].

The structure of sapphire is compact hexagonal, where the height of the c-axis is reported to be $12.96 \AA$ and length $a$ of the basal plane is $4.75 \AA$ leading up to a very high aspect $(c / a)$ ratio of $2.73[6,7,8]$. Sapphire is known to have 8 slip planes resulting in 17 slip systems with dissociated dislocations [9]. The basal or c-slip system is found to be dominant at higher temperatures $[7,9,10,11]$, however it is difficult to observe it 
at room temperature [12]. However, fracture and twinning as two main mechanism of deformation in sapphire at room temperature have been observed in nanoindentation experiments. The principal twinning systems observed in sapphire are basal (C) and rhombohedral (R) twinning [10, 13 ]. Therefore, studying the mechanical anisotropy of sapphire is crucial for improving its processing parameters; in other words, understanding the effects of crystal structure on the deformation and crack propagation of sapphire is essential for the successful application of this material.

Indentation is one of the most commonly employed methods for studying the deformation and fracture mechanisms of materials. The elastic-plastic behaviour of the $c$-plane of single-crystal sapphire was evaluated by Mao et al. [14] using ultra-low nanoindentation loads with a Berkovich indenter. Multiple nanoscale pop-in behavior of the c-plane of sapphire was observed by nanoindentation experiments at room temperature. The width of the pop-ins was observed to increase at lower loading rates. The indentation size effect (ISE) was also observed in the hardness values. Those authors chose also a Berkovich indenter to investigate the pop-in behavior and the mechanical properties of the $R$-plane of sapphire [15]. The effect of loading rate on popin load and its extension was observed up to the indentation depth of $120 \mathrm{~nm}$. They also reported the indentation size effect in the hardness value at sub-60 $\mathrm{nm}$ depth. On the other hand, Bhattacharya et al. [16] studied the effect of loading rate on the nanohardness of sapphire. A significant increase in the nanohardness value ( $66 \%)$ with the increase in the loading rate from 10 to $1000 \mu \mathrm{N} \mathrm{s}^{-1}$ was observed. The maximum shear stress ( 5 to $20 \mathrm{GPa}$ ) generated underneath the indenter increased with the loading rate and was greater than the theoretical shear stress $(0.34 \mathrm{GPa})$ of the sapphire. These 
studies have been mainly conducted at the nanometer scale, while numerous articles have investigated the processing mechanisms of sapphire at the micron scale. Nowak et al. [17] discussed the singularity that was observed in the loading cycle of the indentation hysteresis loop for sapphire when indented by a spherical tip with a radius of $5 \mu \mathrm{m}$ at a maximum load of $500 \mathrm{mN}$. Guillou et al. [18] studied the crack initiation and propagation of sapphire under contact fatigue conditions using the soft impresser technique. The sapphire deformed after only one cycle with the use of harder $\mathrm{WC} / \mathrm{Co}$ impresser. It was also observed that the cyclic induced plastic deformation occurs slowly in sapphire crystal and at high impresser load. The reason could be the dislocation and twinning of these materials. The mechanical properties of sapphire at the micrometer and sub-micrometer length scales have generally been studied via nanoindentation experiments, however, there are a few studies which reports the compression of micron sized pillars at room temperature. Montagne et al. [19] have investigated different deformation modes of four common orientations of sapphire namely, $\left\langle 0001>\mathrm{C},\left\langle 112 ;^{-} 0\right\rangle \mathrm{A},\left\langle 101 ;^{-} 0\right\rangle \mathrm{M}\right.$ and $\left\langle 011 ;^{-} 2\right\rangle \mathrm{R}$ planes using in-situ micro pillar compression testing at room temperature. The deformation of the pillars for each orientation was analyzed using Schmidt's laws and geometric observations. They reported several deformation mechanisms such as cracking and plasticity and the probability of each event happening depended strongly on the orientation. Therefore, for the same size of pillars, pillars oriented along $\left\langle 12 ;^{-} 10\right\rangle$ were more prone to deform plastically than those along $\left\langle 101 ;^{-} 0\right\rangle$ orientation. When plastic deformation of the pillars occurred, the stress was three times lower than the theoretical shear stress. It was concluded that the initiated plasticity was nucleation dominated which resulted in a 
relatively lower stress level required for the onset of plasticity as compared to their theoretical shear strength.

It is known that the pop-ins reflect an unambiguous transition from reversible (predominantly elastic) to irreversible plastic deformation during the earliest stages of mechanical contact in indentation experiments [20,21]. Nanoindentation studies have also shown that fracture and twinning are the main mechanisms responsible for deformation of sapphire at room temperature. As it was already mentioned, two types of twinning systems are typically reported in sapphire: basal (c-plane) and rhombohedral $(R$-plane) twinning [10, 13].

This paper aims to get a better fundamental understanding of the effect of crystal orientation on the deformation process and cracking behaviour of sapphire at the micron and sub-micron length scales. To achieve this goal, we performed a systematic study on the four main crystallographic planes ( $a$-plane, $c$-plane, $m$-plane and $R$-plane) on sapphire samples produced by the Verneuil method by means of nanoindentation using spherical indenters. It also aims at understanding the physical origin of the pop-in present in the load-displacement curves.

\section{EXPERIMENTAL METHODS}

\subsection{Materials}

Figure 1 shows the most often used crystallographic planes of sapphire. Accordingly, those are the crystallographic orientations chosen to be studied in the present paper; i.e. prismatic "a-plane" (112; $\left.;^{-}\right)$, basal " $c$-plane" (0001), prismatic " $m$-plane" $\left(11 ;^{-} 00\right)$ and 
rhombohedral "R-plane" $\left(11 ;^{-} 02\right)$ planes. All samples were fabricated by the Verneuil method and supplied by Stettler Sapphire AG (Switzerland). It was determined by X-ray measurements that the samples had a maximum misorientation angle of $2^{\circ}$ with respect to the crystal growth direction. The samples were discs of $3 \mathrm{~cm}$ diameter and $3 \mathrm{~mm}$ thickness and both sides were mirror-like polished.

\subsection{Experiments}

The nanoindentation experiments were performed on an MTS Nano-Indenter XP (MTS/Nanoinstruments, Oak Ridge, TN) equipped with a lateral force measurement option. To determine the proper effect of crystallographic orientation on the deformation and cracking behavior of sapphire, the choice of the indenter shape is of utmost importance. It is well known that during nanoindentation experiments, when using non-spherical indenters, the deformation and crack patterns are not only dependent on the crystallography of the sample, but it is also influenced by the tip geometry; e.g. cracks always start at the tip edges due to stress concentration at these locations [22]. Hence, spherical indenters were chosen to avoid the influence of the tip geometry in the stress distribution on the sample during the test and so to measure the true deformation and fracture behavior of sapphire.

Three types of spherical tips have been used in this work:

- Spherical indenter with an apex angle of $60^{\circ}$ and a tip radius of $1 \mu \mathrm{m}$.

- Spherical indenter with an apex angle of $120^{\circ}$ and a tip radius of $2 \mu \mathrm{m}$.

- Spherical indenter with an apex angle of $120^{\circ}$ and a tip radius $10 \mu \mathrm{m}$.

For the systematic study of deformation, indenting loads up to $600 \mathrm{mN}$ were used depending on the indenter tip radius. To investigate the cracking behavior, the applied 
indenting loads ranged from 100 to $600 \mathrm{mN}$ by steps of $100 \mathrm{mN}$. For all experiments, the loading and unloading rate was $10 \mathrm{mN} / \mathrm{s}$ without holding time at the maximum load. All residual indentation marks were examined by optical microscopy. The detailed features were inspected using a High-Resolution Scanning Electron Microscope (HRSEM), Hitachi S-4800 FEG-SEM (Hitachi, Japan). A CM20 Philips Transmission Electron Microscope (TEM) operating at an accelerating voltage of $200 \mathrm{kV}$ with a $\mathrm{LaB}_{6}$ source (point resolution $2.8 \AA$ ) was employed to evaluate the subsurface damages after indentations. The TEM samples were fabricated by cross sectioning the indent using the Focused Ion Beam (FIB) in a FEI Strata DB 235 equipment.

The crystal orientations were determined using the Electron Back Scattered Diffraction (EBSD) imaging obtained by a Zeiss DSM 962 Scanning Electron Microscope (SEM).

\section{RESULTS AND DISCUSSION}

\subsection{Nanoindentation deformation}

The numerical data obtained from the nanoindentation tests performed with the spherical tips were plotted for every crystallographic orientation in the form of loaddisplacement curves. In all cases, those curves present a discontinuity or "pop-in", that reflects a phenomenon or combination of phenomena (e.g. dislocation nucleation, crack initiation) taking place in the material. Figure 2 includes representative loaddisplacement curves for each plane studied in the present work in which the "pop-in" is evident (blue plots).

Although the load at which the "pop-in" takes place varies slightly between experiments on the same plane (see Table 1), the crystallographic orientation has an impact on the 
"pop-in" load and the evidence of this is seen in Table 1 that summarizes the mean and standard values at which the "pop-in" occurs for each orientation. The lowest "pop-in" load corresponds to the $R$-plane, being the load for the other planes quite similar. It is also very important to note that, in all cases, if the indentation load is below the one of the "pop-in", then sapphire shows a pure elastic behavior (red plots).

Since all planes show a similar behavior, the $a$-plane was selected to inspect the indents by HR-SEM. Figure 3 includes the HR-SEM micrographs of the indentation areas corresponding to a maximum load of $20 \mathrm{mN}$ (load-displacement curve shows elastic behavior) and a maximum load of $50 \mathrm{mN}$ (load-displacement curve shows "pop-in"). As seen, there is no indent imprint when indenting at $20 \mathrm{mN}$. This confirms the elastic recovery of sapphire and the absence of plastic deformation. In contrast, at $50 \mathrm{mN}$, plastic deformation is evident (Figure $3 b$ ) which can be divided in two categories: a large plastic zone and two twins. It is interesting to note that the large plastic zone does not follow the spherical type (round shape) and it is closed to a hexagonal shape. Same for the two large twins pointed out in Figure 3b, they look to follow a specific crystallographic plane and propagate outside the large plastic zone.

From the presented results, it is proven that sapphire shows a pure elastic behavior before the "pop-in". Hence, understanding the cause of the "pop-in" will bring light into the fundamental understanding of the deformation and fracture mechanisms of sapphire.

To determine the origin of the "pop-in", indentation experiments were performed in a way that the load was increased until the detection of the "pop-in", followed by direct unloading as shown in Figure 4. The idea behind these tests was to make sure that the 
microstructural features of the corresponding indentations are a direct consequence of the "pop-in" event, since the behavior of sapphire prior to the "pop-in" is purely elastic (Figure 2). Additionally, all the experiments were performed with two different tip radii (10 and $1 \mu \mathrm{m}$ ) to see whether the origin of the pop-in is dependent on the load/stress at which it takes place.

The load-displacements curves with the tip radius of 10 and $1 \mu \mathrm{m}$ are presented in Figure 4. As expected, the load at which the "pop-in" appears is different for different tip radius. The "pop-in" appears at 550 and $8.4 \mathrm{mN}$ for the tip radius of 10 and $1 \mu \mathrm{m}$, respectively. Interestingly, despite the differences in the tip geometry, the corresponding shear stresses are similar, that is at 24.7 and $28.4 \mathrm{GPa}$, respectively.

The HR-SEM micrographs of the corresponding indents are shown in Figure 5. From these figures and as expected, the size of the corresponding indents also differs very much: $4 \mu \mathrm{m}$ (not considering the cracks) for the $10 \mu \mathrm{m}$ spherical tip and $0.5 \mu \mathrm{m}$ for the $1 \mu \mathrm{m}$ spherical tip indenter. However, the main difference is that both slip bands and cracks are observed for the indents using the $10 \mu \mathrm{m}$ spherical tip indenter whereas only slip bands with no cracks are detected in the indents performed with the $1 \mu \mathrm{m}$ tip. Although sapphire is known to be a very hard and brittle material, this fact suggests that the deformation mechanisms of sapphire depend on the stress applied on the material.

TEM characterization of the indents confirmed this hypothesis and the results are shown in Figure 6 and Figure 7. In these figures, a protective platinum layer has been deposited to avoid damage and ion implementation during the lamella preparation. TEM observation of the damage area beneath the nanoindentation locations reveals complex 
zones of cracks and varying local strains for the $10 \mu \mathrm{m}$ tip (Figure 6) and only complex zones of varying local strains for the $1 \mu \mathrm{m}$ tip (Figure 7). Several bend contours are visible in Figure 6 and Figure 7, that correspond to an increase of stress within the sample [23]. Detailed explanation of the formation of such contours is reported elsewhere [24].

The fact that cracking occurs only for the large indenter $(10 \mu \mathrm{m})$ proves that the deformation mechanisms of sapphire are size dependent, a phenomenon well known in the field of indentation [25]. It is believed that the difference between both indenters is related to the energy dissipation via deformation and cracking. Actually, the accumulated energy during the loading part prior the "pop-in" in the case of the $10 \mu \mathrm{m}$ indenter is much larger than the energy for the $1 \mu \mathrm{m}$ indenter. Considering that the "pop-in" time for both experiments is similar (some tens of seconds), that implies that the potential energy to be dissipated for the $10 \mu \mathrm{m}$ indenter is much larger as compared to the one for the $1 \mu \mathrm{m}$ indenter. Thus, in addition to the deformation via slip bands, a very efficient way to dissipate this energy is by cracking the material. Cracks nucleate and propagate to relieve the high local stresses generated during the indentation process. This agrees with previous works in semiconductors [26, 27]. For the indentation experiments of sapphire at room-temperature, it is also confirmed that twinning and fracture are the main mechanisms responsible for the deformation of sapphire [28, 29]. Thus, a sudden increase of plasticity represents a twinning process or twining-fracture process which occurs under the indenter. In the present work, it is proven that the deformation mechanism is different depending on the applied stress. 


\subsection{Nanoindentation cracking}

As mentioned in the introduction, sapphire is often manufactured by grinding $[2,3]$ in which the more advanced models assume that material removal occurs by microcracking (median and lateral cracks) and generation of chip fragments [30, 31]. Hence, understanding the fracture of sapphire at variable scales is required. In this work, systematic nanoindentation experiments were performed on the different crystallographic orientations and varying the indenter tip radius and indentation load. Two types of spherical tips were used:

- Spherical indenter with apex angle of $60^{\circ}$ and a tip radius of $1 \mu \mathrm{m}$.

- Spherical indenter with apex angle of $120^{\circ}$ and a tip radius of $2 \mu \mathrm{m}$.

The spherical indenter with a tip radius of $10 \mu \mathrm{m}$ was not considered since the "pop-in" load was higher than $550 \mathrm{mN}$ (See Figure 4a), which is very close to the maximum applied load of the nanoindenter.

\subsubsection{Influence of the load}

The indenting loads applied for each type of tip ranged from 100 to $600 \mathrm{mN}$ by steps of $100 \mathrm{mN}$. Figure 8 includes the representative HR-SEM images of the indents on the $a$ plane of sapphire for the tip with $2 \mu \mathrm{m}$ radius. For all the applied loads, the crack system consists of four cracks. This means that the observed crack pattern is not an artifact and it is actually related to the crystallography of sapphire. The exact orientation of the cracks will be determined and discussed later. As shown in Figure 8, the slip bands are evident in the magnified image of the indent at $600 \mathrm{mN}$. Similar to the crack pattern, the slips bands are also dependent on the crystallographic orientation and this is in consistent with the results presented in Figure 5. 


\subsubsection{Influence of tip radius}

Regarding the $1 \mu \mathrm{m}$ tip radius, it was also observed that, in all cases, the crack system consists of four cracks, as with the $2 \mu \mathrm{m}$ radius tip. Figure 9 includes some representative optical micrographs of the indents on the $a$-plane sapphire for both tips. For the sake of an easy comparison, only indents at 300 and $600 \mathrm{mN}$ are included and the magnification is the same in all pictures.

Not surprisingly, for both tips, the higher the indenting load, the bigger the indent imprint and the longer the originated cracks. When comparing the two indenters at the same load, the damage originated by the tip with smaller radius $(1 \mu \mathrm{m})$ is clearly bigger due to the larger stress involved (ratio between applied load and indenting area). It is very important to note that the tip radius does not affect the crack pattern.

The origin of chipping observed for the $1 \mu \mathrm{m}$ spherical indenter at both loads is due to an interaction between lateral or radial cracks intercepting each other in sapphire [32].

\subsubsection{Influence of the crystallographic orientation}

To investigate the influence of crystallographic orientations, nanoindentations of the other planes ( $c$-plane, $m$-plane, and $R$-plane) were carried out. For the spherical $2 \mu \mathrm{m}$ tip radius at $600 \mathrm{mN}$, the corresponding crack patterns are shown in the representative optical and SEM images included in Figure 10, where the optical images are taken with the same magnification. As observed for the $a$-plane, for all indentation loads (pictures not included), the crack system is reproducible for each plane, meaning that the crack pattern is related to the crystallography of the lattice of sapphire. 
To quantify the crack lengths and determine their crystallographic orientation by Electron Back Scattered Diffraction (EBSD), indents performed using the spherical 2 $\mu \mathrm{m}$ tip at $600 \mathrm{mN}$ were chosen. Pole figures, which are the output of the EBSD analysis, provide direct and complete information about the orientation of the crystal. This information can be used to determine the orientation of the observed cracks on the surface of the sapphire samples. Then, they can be represented in a polar graph, which includes the corresponding crack lengths. Crack lengths were always measured from the center of the indent imprint.

Figure 11 includes the polar plots illustrating the distribution and length of cracks on the four planes studied in the present work. It can be observed that $a$-plane and $c$-plane always show four-crack and six-crack pattern, respectively; and for each pattern, the cracks have approximately the same length. In $m$-plane, four-crack pattern is also visible; however, two cracks are longer than the other two. In $R$-plane, more random distribution of cracks orientation and lengths is seen.

At this point, it is important to explain that the cracks observed at the surface of sapphire and represented in the polar plots are the traces of the actual cracking planes (e.g. Figure 5, Figure 8 and Figure 9). Although the cracking plane gives a certain trace on the surface, it is not necessarily perpendicular to the surface of the sample as evidence in the optical images in Figure 9, where chips can be visible. In Figure 1, it can be seen that, as an example, how both the prismatic (perpendicular to the surface) and rhombohedral planes (oblique) can potentially create the same type of traces (i.e., cracks on the surface) on the basal $c$-plane. 
Therefore, to determine the real cracking planes, it is necessary to work not with the crack traces but with their perpendicular lines. Those indicate the projected lines at the surface of the cracking plane. Then, these projected lines are compared with the obtained pole figures to find the matching figure. This is easier to explain with the help of Figure 12, corresponding to the $a$-plane. The green lines in Figure 12a are perpendicular to the red lines, which are the cracks at the surface (or traces). In other words, the green lines indicate the projection of the cracking plane at the surface. We superimpose the green lines to the several pole figures obtained for the $a$-plane sample (Figure $12 \mathrm{~b})$ and we see that there are three matching planes: the $R$-plane $\left(11 ;^{-} 02\right)$, the $R$-plane $\left(101 ;^{-} 2\right)$ and the $r$-plane $\left(11 ;^{-} 01\right)$. Before determining the actual cracking plane, it is necessary to mention that sometimes there are several degrees of difference between the green line and the poles, but these differences are believed to be due to the experimental error. In fact, several sources of error exist, the two main ones are:

- The SEM image (Figure 12a) and the EBSD mapping were performed in different microscopes. Therefore, there may be a slight misalignment around $2-3^{\circ}$ between the image and the corresponding pole figures (Figure 12b) due to the fact the sample has to be placed manually in the chamber of the microscope.

- The cracks on the surface sample are not totally straight, so an error is introduced when choosing where to draw the red line.

A valid approach to find out which is the actual cracking plane is to compare the real cracks of the sample with the traces of the potential cracking planes generated by the analysis EBSD data software. This is shown in Figure 13. The traces generated by the program are in the left corner of each picture and have been superimposed (red lines) on the SEM picture of the indent. By comparing their corresponding traces generated by 
the software with the real cracks, as it is shown in Figure 13, the plane whose traces best matches all cracks at the surface is the $R$-plane $\left(101 ;^{-} 2\right)$ and therefore this must be the cracking plane. Actually, knowing that the $R$-plane is well known as being a low energy cleavage plane family for sapphire $[6,33,34]$, it becomes evident that the $R$-plane is the actual cracking plane. It is important to note here that in sapphire, there are six " $R$ " equivalent planes. In this work we demonstrate that, despite existing six " $R$ " planes, cracking takes place in the $\left(101 ;^{-} 2\right)$ plane and not in the other ones.

Using the same approach explained before for the $a$-plane, it is found that for the $c$ plane and $m$-plane, the cracking plane is also the $R$-plane. In the case of indentation on the $R$-plane, the more random distribution of the cracks did not make it possible to determine a reproducible cracking plane. This erratic cracking behavior of $R$-plane was already detected and reported by the authors in a previous work [34]. It can be explained by two facts:

- $\quad$ The $a$-plane and the $m$-plane have similar values of fracture toughness [34]. Therefore, when indenting on the $R$-plane, the crack does not tend to propagate preferentially in any plane, and that may be the cause of a random propagation trajectory.

- In fact, sapphire possesses numerous crystallographic planes [6], many more than the ones considered in this work. Information in the literature concerning the mechanical properties of those rare forms of sapphire is very limited. If their value of fracture toughness was similar to the one of $a$-plane and the $m$-plane, that would support the erratic behavior of cracks when indenting on the $R$-plane. 


\section{CONCLUSIONS}

In this work, nanoindentation experiments using spherical indenters on sapphire produced by the Verneuil method have been reported. The effect of the applied load, the crystallographic orientation ( $a-, c-, m$ - and $R$-planes) and the tip radius has been investigated. The tested samples were inspected via the nanoindentation loaddisplacement curves, SEM, including EBSD, and TEM. The results were analyzed based on the deformation and cracking processes.

It is found that the deformation mechanisms of sapphire depend on the applied stress on the material, as confirmed by TEM analyses: exclusively twin formation at low stress and twin formation together with cracks propagation at high stress. This was explained by the way the energy dissipation takes place. At low stress, the accumulated energy prior the pop-in is not sufficient to initiate cracks and therefore only twinning can take place. In contrast, at high stress, the energy accumulated is much larger, so that twinning does not dissipate sufficiently fast the energy and cracking is taking place. When considering the crack pattern, we found that it does not depend on the radius of the spherical tip neither on the applied load. In other words, the crack pattern depends exclusively on the crystallographic orientation of the indented plane: 6 cracks of the same length for the "c-plane"; 4 cracks of the same length for the " $a$-plane"; 4 cracks of different lengths (2 longer than the other 2 ) for the " $m$-plane"; more random distribution of cracks for the " $R$-plane". Hence, we can conclude that the crystallographic orientation of the sapphire plays a major role in the cracking behavior.

It was also demonstrated that although sapphire has several low energy cleavage plane families, for " $a$-plane ", " $c$-plane " and " $m$-plane " planes, the most probable cracking 
plane is $\left(101 ;^{-} 2\right)$, i.e. the " $R$-plane" plane. This finding is consistent with the fracture mechanics principle. For the " $R$-plane", the cracking behavior is found to be random. This is explained by two facts: first, difference in the fracture toughness value between the " $a$-plane" and "m-plane" is relatively small; second, sapphire has many more planes than the main ones investigated in this study. Most of those planes are intermediate between the " $c$-plane" and " $m$-plane" and very little information is available about them.

As expected from fracture mechanics, the applied load, the tip radius and the tip angle influence the crack length and depth and thus, the degree of chipping. The higher the indenting load, the longer the created cracks. The sharper the tip, the higher the stress and as a consequence, more severe chipping is created.

\section{Acknowledgements}

The authors would like to thank the Swiss Commission for Technology and Innovation (CTI - project GrindSaf, 10610.2 PFIW-IW) for the financial support of this work. Stettler Sapphire AG is acknowledged for supplying the sapphire samples. SP acknowledges support from NSF MRI \#1726897 and NSF \#1841331.

\section{References}

[1] C.D. Jones, J.B. Rioux, J.W. Locher, H.E. Bates, S.A. Zanella, V. Pluen, M.

Mandelartz, Large-area sapphire for transparent armor, American Ceramic Society Bulletin 85 (2006) 24-26. 
[2] K. Wasmer, P.M. Pochon, D. Sage, J. H. Giovanola, Parametric experimental study and design of experiment modelling of sapphire grinding, J. Clean. Prod. 141 (2017) 323-335. https://doi.org/10.1016/j.jclepro.2016.09.031

[3] P.D. Funkenbusch, Y. Zhou, T. Takahashi, D. Golini ${ }_{s}$ Grinding of single crystal sapphire: workpiece roughness correlations. Wear 218 (1998) 1-7. doi:10.1016/S00431648(98)00206-3.

[4] T-C. Chen, R. Darling, Parametric studies on pulsed near UV frequency tripled Nd:YAG laser micromachining of sapphire and silicon, J. Mat. Proc. Techn. 169, (2005) 214-218. https://doi.org/10.1016/j.jmatprotec.2005.03.023

[5] F. Saeidi, F. Mouhamadali, K. Wasmer, Nanosecond laser ablation of different crystallographic planes of sapphire, Presented at Laser in Manufacturing - LiM 2017, München, Germany, 26 - 29 June 2017.

[6] "Sapphire: material, manufacturing, application". E. R. Dobrovinskaya, L. A. Lytvynov, V. Pishchik, Springer, 2009.

[7] M. L. Kronberg, Plastic deformation of single crystals of sapphire: Basal slip and twinning, Acta Metall., 5 (9) (1957) 507-524. https://doi.org/10.1016/0001$\underline{6160(57) 90090-1}$

[8] A. H. Heuer, K. P. D. Lagerlöf, J. Castaing, Slip and twinning dislocations in sapphire $\left(\alpha-\mathrm{Al}_{2} \mathrm{O}_{3}\right)$, Philos. Mag. A, 78(3) (1998) 747-763. doi:10.1080/01418619808241934

[9] J. D. Snow, A. H. Heuer, Slip systems in $\mathrm{Al}_{2} \mathrm{O}_{3}$, J. Am. Ceram. Soc., 56(3) (1973) 153-157. doi:10.1111/j.1151-2916.1973.tb15432.x 
[10] K. P. D. Lagerlöf, A. H. Heuer , J. Castaing, J. P. Rivière, T. E. Mitchell, Slip and twinning in sapphire $\left(\alpha-\mathrm{Al}_{2} \mathrm{O}_{3}\right)$, J. Am. Ceram. Soc., 77(2), (1994) 385-397. doi:10.1111/j.1151-2916.1994.tb07006.x

[11] A. Nakamura, T. Yamamoto, Y. Ikuhara, Direct observation of basal dislocation in sapphire by HRTEM, Acta Mater., 50(1) (2002) 101-108.

https://doi.org/10.1016/S1359-6454(01)00318-4

[12] W. Kollenberg, Plastic deformation of $\mathrm{Al}_{2} \mathrm{O}_{3}$ single crystals by indentation at temperatures up to $750^{\circ} \mathrm{C}$, J. Mat. Sci., 23(9) (1988) 3321-3325.

doi:10.1007/BF00551312

[13] T. Geipel, K. P. D. Lagerlöf, P. Pirouz, A. H. Heuer, A zonal dislocation mechanism for rhombohedral twinning in sapphire $\left(\alpha-\mathrm{Al}_{2} \mathrm{O}_{3}\right)$, Acta Metall. et Mater., 42(4) (1994) 1367-1372. doi:https://doi.org/10.1016/0956-7151(94)90154-6

[14] W.G. Mao, Y.G. Shen, C. Lu, Nanoscale elastic-plastic deformation and stress distributions of the c plane of sapphire single crystal during nanoindentation. J. Eur. Ceram. Soc. 31 (2011) 1865-1871, doi:10.1016/j.jeurceramsoc.2011.04.012.

[15] W. Mao, Y. Shen, Nanoindentation study of pop-in phenomenon characteristics and mechanical properties of sapphire $\left(1012 ;^{-}\right)$crystal, J. Am. Ceram. Soc. 95 (2012) 3605-3612, doi:10.1111/j.1551-2916.2012.05405.x.

[16] M. Bhattacharya, A. Dey, A.K. Mukhopadhyay, Influence of loading rate on nanohardness of sapphire, Ceram. Int. 42 (2016) 13378-13386, doi:10.1016/j.ceramint.2016.05.091.

[17] R. Nowak, T. Sekino, S. Maruno, K. Niihara, Deformation of sapphire induced by a spherical indentation on the (1010) plane, Appl. Phys. Lett. 68 (1996) 1063-1065 doi:10.1063/1.115713. 
[18] M.O. Guillou, J.L. Henshall, R.M. Hooper, Indentation fracture and soft impresser fatigue in sapphire and polycrystalline alumina. Int. J. Refract. Met. Hard Mater. 16 (1998), 323-329, https://doi.org/10.1016/S0263-4368(98)00041-9

[19] A. Montagne, S. Pathak, X. Maeder, J. Michler, Plasticity and fracture of sapphire at room temperature: Load-controlled microcompression of four different orientations. Ceram. Int., 40(1, Part B) (2014) 2083-2090.

https://doi.org/10.1016/j.ceramint.2013.07.121

[20] C. A. Schuh, A. C. Lund, Application of nucleation theory to the rate dependence of incipient plasticity during nanoindentation, J. Mater. Res. 19 (2004) 2152-2158, https://doi.org/10.1557/JMR.2004.0276

[21] S. Pathak, J. L. Riesterer, S. R. Kalidindi, J. Michler, Understanding pop-ins in spherical nanoindentation, App. Phys. Lett. 105, 161913 (2014). doi:

$10.1063 / 1.4898698$

[22] N. Wang, F. Jiang, X. Xu and X. Lu, Effects of crystal orientation on the crack propagation of sapphire by sequential indentation testing, Crystals 8 (2018) 3, doi:10.3390/cryst8010003

[23] E.A. Stach, T. Freeman, A.M. Minor, D.K. Owen, J. Cumings, M.A. Wall, T. Chraska, R. Hull, J.W. Morris, A. Zettl, U. Dahmen, Development of a nanoindenter for in situ transmission electron microscopy, Microsc. Microanal. 7(6) (2001) 507-517, https://doi.org/10.1007/S10005-001-0012-4

[24] F. ElFallagh, A. Lockwood, B. Inkson, In-situ TEM observation of deformations in a single crystal sapphire during nanoindentation, A. Öchnser and H. Altenbach (eds.), Experimental and Numerical Investigation of Advanced Materials and Structures, 
Advanced Structured Materials 41, Springer International Publishing Switzerland 2013. doi: 10.1007/978-3-319-00506-5_16

[25] J.G. Swadener, E.P. George, G.M. Pharr, The correlation of the indentation size effect measured with indenters of various shapes, J. Mech. Phys. Solids. 50 (2002) 681694, https://doi.org/10.1016/S0022-5096(01)00103-X

[26] K. Wasmer, C. Pouvreau, J.-M. Breguet, J. Michler, D. Schulz, J.H. Giovanola, Nanoindentation cracking in Gallium Arsenide: Part I: In Situ SEM Nanoindentation, J. Mat. Res. 28 (2013) 2785-2798, http://dx.doi.org/10.1557/jmr.2013.252

[27] K. Wasmer, R. Gassilloud, C. Ballif, J. Michler, Analysis of onset of dislocation nucleation during nanoindentation and nanoscratching of InP, J. Mat. Res., 27 (2012) 320-329, http://dx.doi.org/10.1557/jmr.2011.305.

[28] B.Y. Farber, S.Y. Yoon, K.P.D. Lagelöf, A.H. Heuer, Dislocation sources in sapphire $\left(\alpha-\mathrm{Al}_{2} \mathrm{O}_{3}\right)$ near microhardness indents. Z. Metallkd. 84 (1993), 426-430. [29] B.Y. Farber, S.Y. Yoon, K.P.D. Lagelöf, A.H. Heuer, Microplasticity during high temperature indentation and the Peierls potential in sapphire $\left(\alpha-\mathrm{Al}_{2} \mathrm{O}_{3}\right)$ single crystals, Phys. Status Solidi A 137 (1993) 485-498, https://doi.org/10.1002/pssa.2211370219 [30] A.G. Evans, D.B. Marshall, Wear Mechanisms in Ceramics. Fundamentals of Friction and Wear of Materials, ASM Materials Science, 439-452 (1980), Pittsburgh, PA, USA.

[31] S. Malkin, T.W. Hwang, Grinding mechanisms for ceramics. Keynote Paper Ann. CIRP Manuf. Technol. 45 (1996) 569-580, https://doi.org/10.1016/S0007$\underline{8506(07) 60511-3 .}$.

[32] "Fracture of brittle solids"; B. Lawn, Cambridges solid state science series, $2^{\text {nd }}$ Edition, 1993. 
[33] B.J. Pletka, T.E. Mitchell, A.H. Heuer, Solid solution hardening of sapphire ( $\alpha-$ $\mathrm{Al}_{2} \mathrm{O}_{3}$ ), Phys. Stat. Sol. 39 (1977) 301-311, https://doi.org/10.1002/pssa.2210390135 [34] S. Graça, V. Trabadelo, A. Neels, J. Kuebler, V. Le Nader, G. Gamez, M. Döbeli, K. Wasmer, Influence of mosaicity on the fracture behavior of sapphire, Acta Mater. 67 (2014) 67-80. doi:10.1016/j.actamat.2013.12.004. 


\section{$\underline{\text { Figure captions }}$}

Figure 1. Location of the crystallographic planes of sapphire often met in practice [6].

Figure 2. Nanoindentation load-displacement curves for the different planes of Verneuil sapphire indented with a spherical tip of $2 \mu \mathrm{m}$ radius. The maximum indentation load is $50 \mathrm{mN}$ for the blue curves and $20 \mathrm{mN}$ for the red curves. The red curves show a typical elastic behavior, since the displacement on the surface of sapphire after unloading is zero.

Figure 3. Representative load-displacement curves and HR-SEM micrographs of the corresponding indentation areas on the $a$-plane of sapphire for a maximum indentation load of: a) $20 \mathrm{mN}$ and b) $50 \mathrm{mN}$ with a spherical tip of $2 \mu \mathrm{m}$ radius.

Figure 4. Load-displacement curves of a nanoindentation test performed on the $a$-plane of sapphire and stopped right after the "pop-in" using spherical tip with different radius: a) $10 \mu \mathrm{m}$ spherical tip; b) $1 \mu \mathrm{m}$ spherical tip.

Figure 5. HR-SEM pictures of indents on the $a$-plane stopped right after the "pop-in" for both the $10 \mu \mathrm{m}$ spherical tip indenter (top) and the $1 \mu \mathrm{m}$ spherical tip indenter (bottom). Cracks and twins are indicated by arrows. 
Figure 6. TEM pictures corresponding to the indent shown in Figure 5 that was performed using the $10 \mu \mathrm{m}$ spherical tip indenter. A protective platinum layer has been deposited to avoid damage and ion implementation during the lamella preparation.

Figure 7. TEM pictures corresponding to the indent shown in Figure 5 performed with the $1 \mu \mathrm{m}$ spherical tip indenter. No cracks are observed. A protective platinum layer has been deposited to avoid damage and ion implementation during the lamella preparation.

Figure 8. HR-SEM micrographs for Verneuil $a$-plane for the different indentation loads. All indents were performed with a spherical tip indenter with $2 \mu$ m radius. The bottom figure is a zoom-in from the $600 \mathrm{mN}$ to show detail of the plastic deformation below the indenter.

Figure 9. Optical micrographs of indents in $a$-plane sapphire (all taken at the same magnification) for both the $2 \mu \mathrm{m}$ and $1 \mu \mathrm{m}$ spherical indenters at $300 \mathrm{mN}$ and $600 \mathrm{mN}$. The SEM pictures of the indents performed with the $2 \mu \mathrm{m}$ tip have been included to facilitate the comparison.

Figure 10. Optical (top) and SEM (bottom) pictures of indents in sapphire at $600 \mathrm{mN}$ using the $2 \mu \mathrm{m}$ tip spherical indenter. The three optical images have the same magnification. 
Figure 11. Polar plots of the distribution of the cracks $(2 \mu \mathrm{m}$ spherical indenter, $600 \mathrm{mN}$ indentation load) on different planes of sapphire. The grey circle represents in all cases the indentation imprint.

Figure 12. a) One of the indents on $a$-plane used for the EBSD measurement and oriented as indicated in Figure 11. Red lines: cracks (or cracking plane traces); green lines: perpendicular to the red lines indicating the projection of the crack orientation at the surface; b) Pole figures corresponding to the $a$-plane sample. The green lines are the same lines as in Figure 12a.

Figure 13. Comparison of the cracks on the surface with the traces generated by the software for the three potential cracking planes in the $a$-plane sample. 
$\underline{\text { Tables }}$

Table 1: Summary of the pop-in results of the Verneuil sapphire

\begin{tabular}{|c|c|c|c|c|}
\hline & $c$-plane & $a$-plane & $m$-plane & $R$-plane \\
\hline $\begin{array}{c}\text { Mean load } \\
{[\mathrm{mN}]}\end{array}$ & 27.6 & 24.3 & 25.6 & 18.5 \\
\hline $\begin{array}{c}\text { St. dev. } \\
{[\mathrm{mN}]}\end{array}$ & \pm 2.5 & \pm 2.9 & \pm 2.1 & \pm 3.5 \\
\hline
\end{tabular}



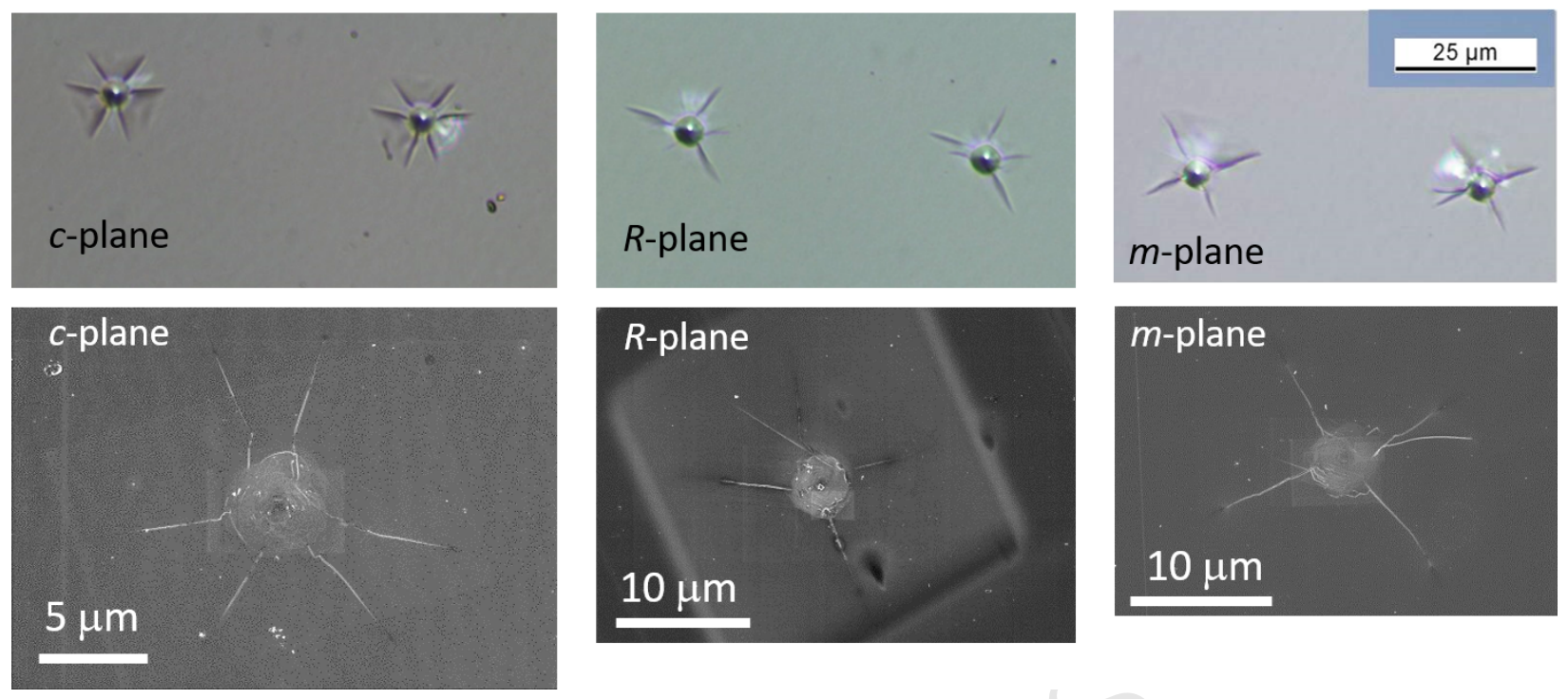

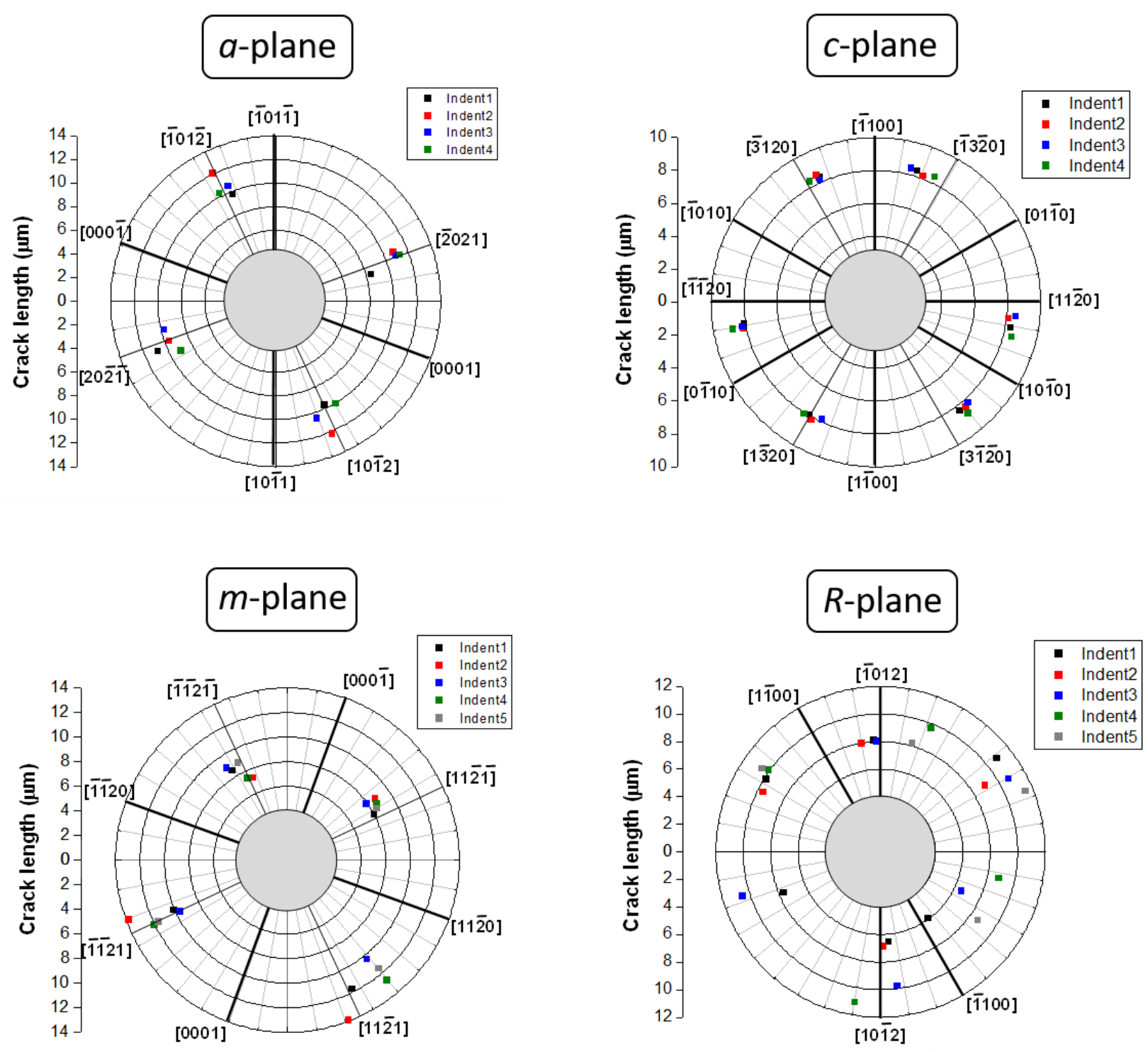


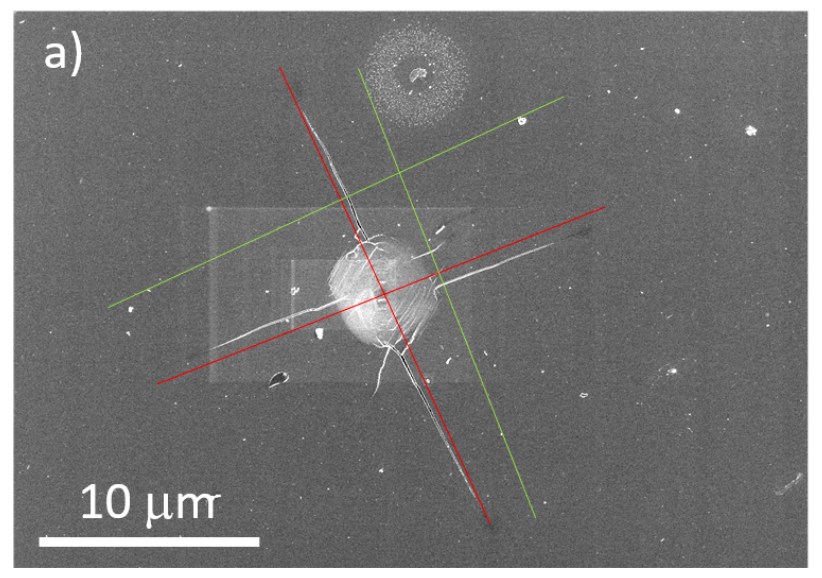

b)
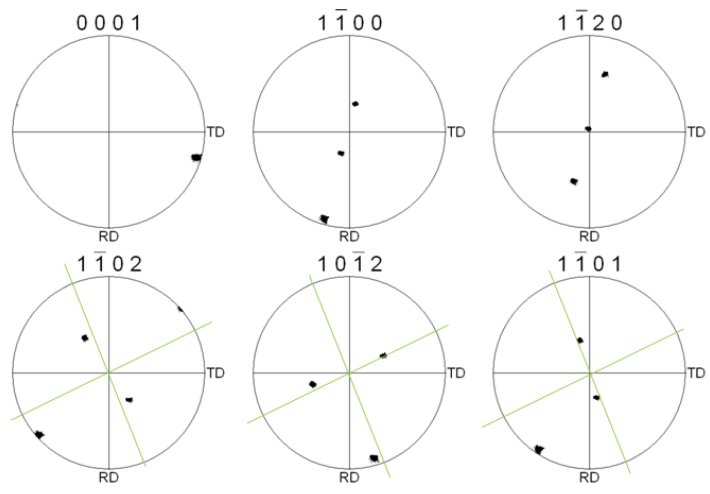


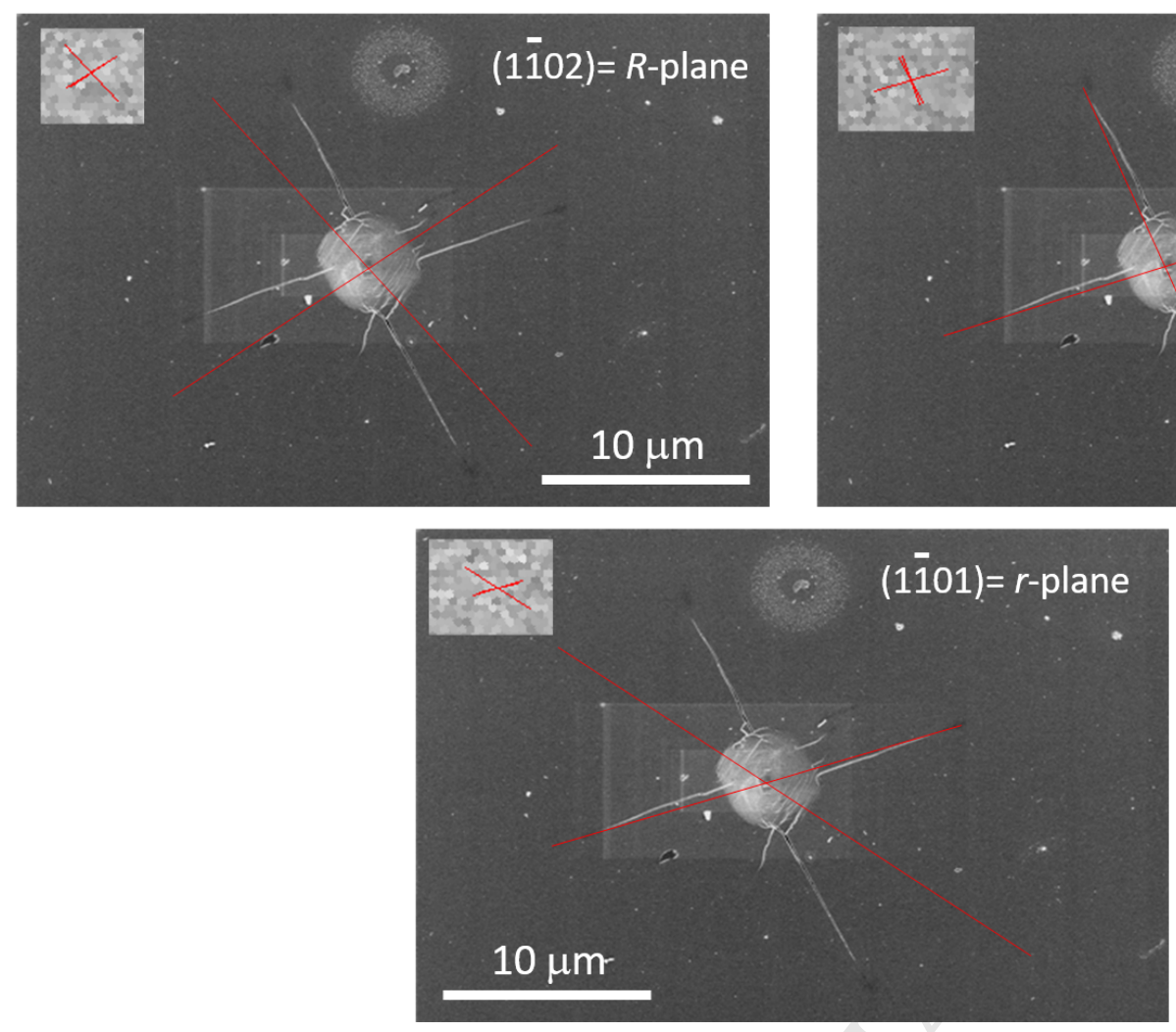

$10 \mu \mathrm{m}$

$(10 \overline{1} 2)=R$-plane

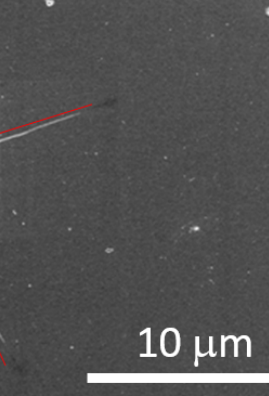




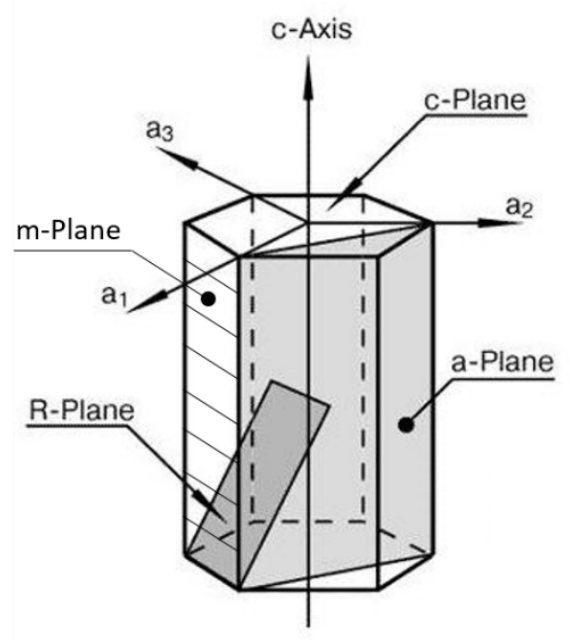



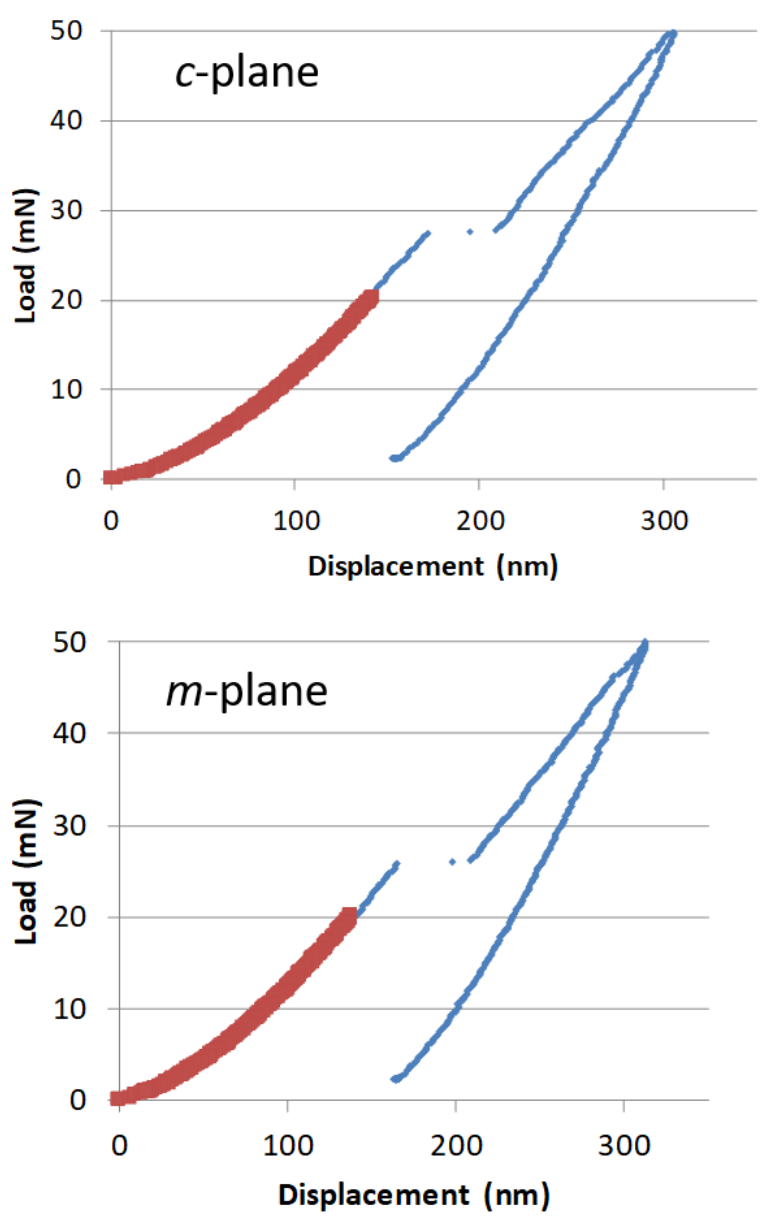
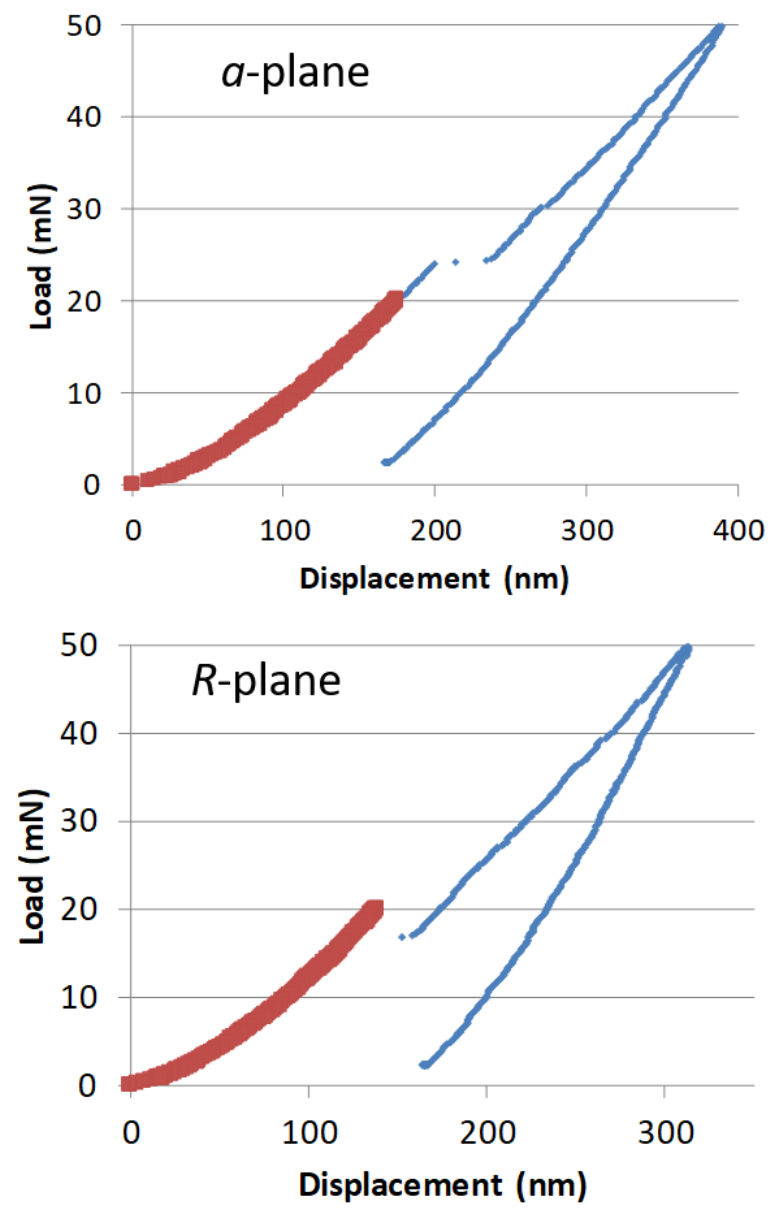
a)

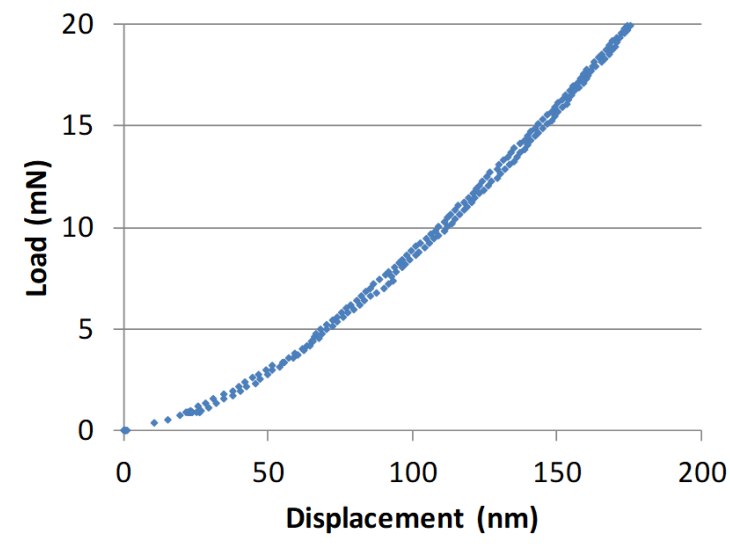

b)

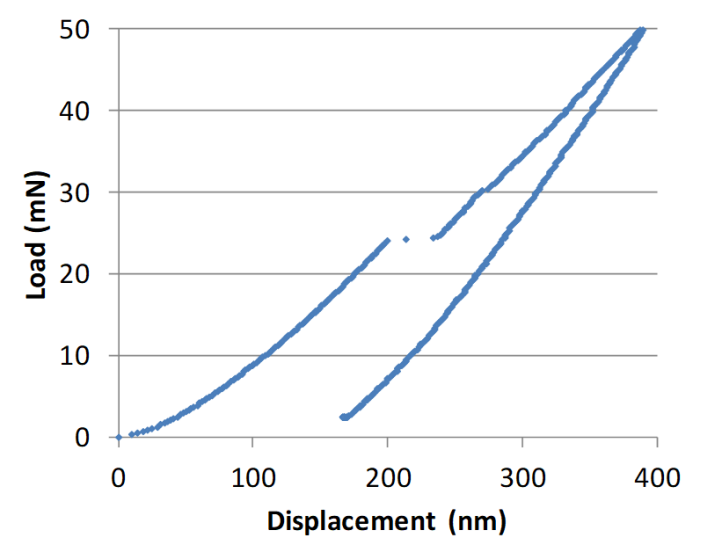

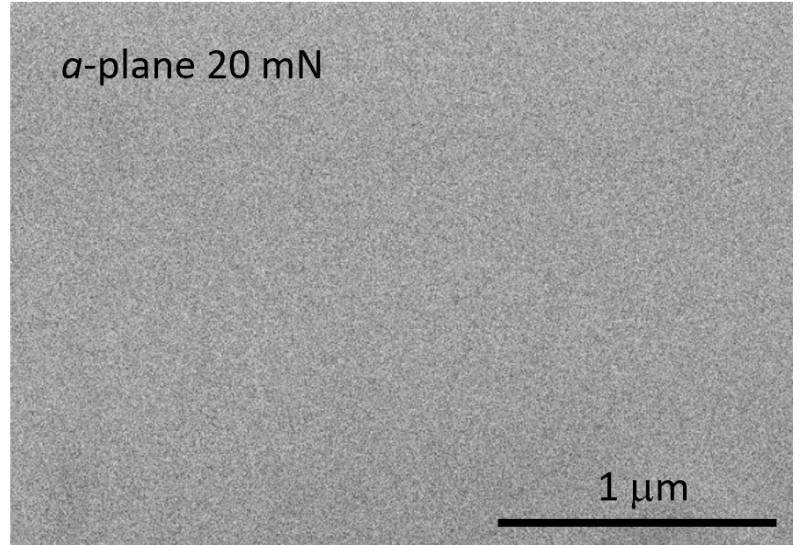

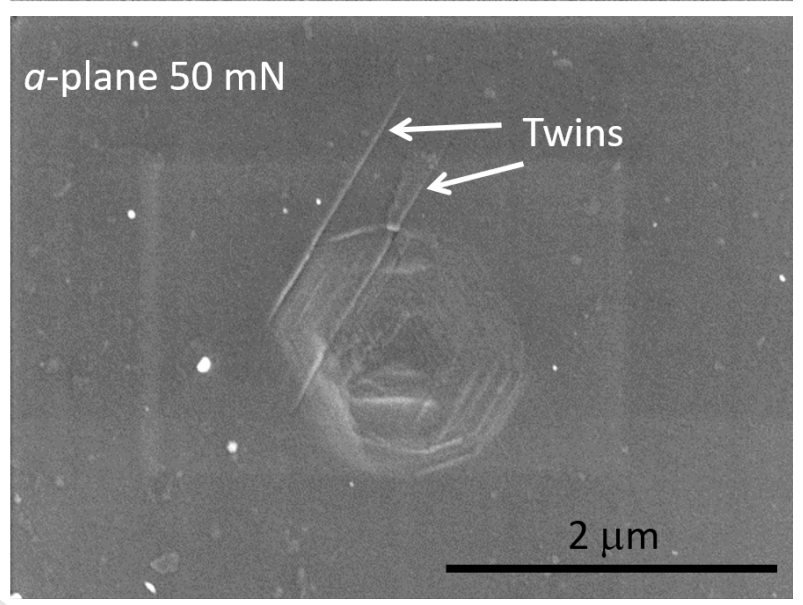



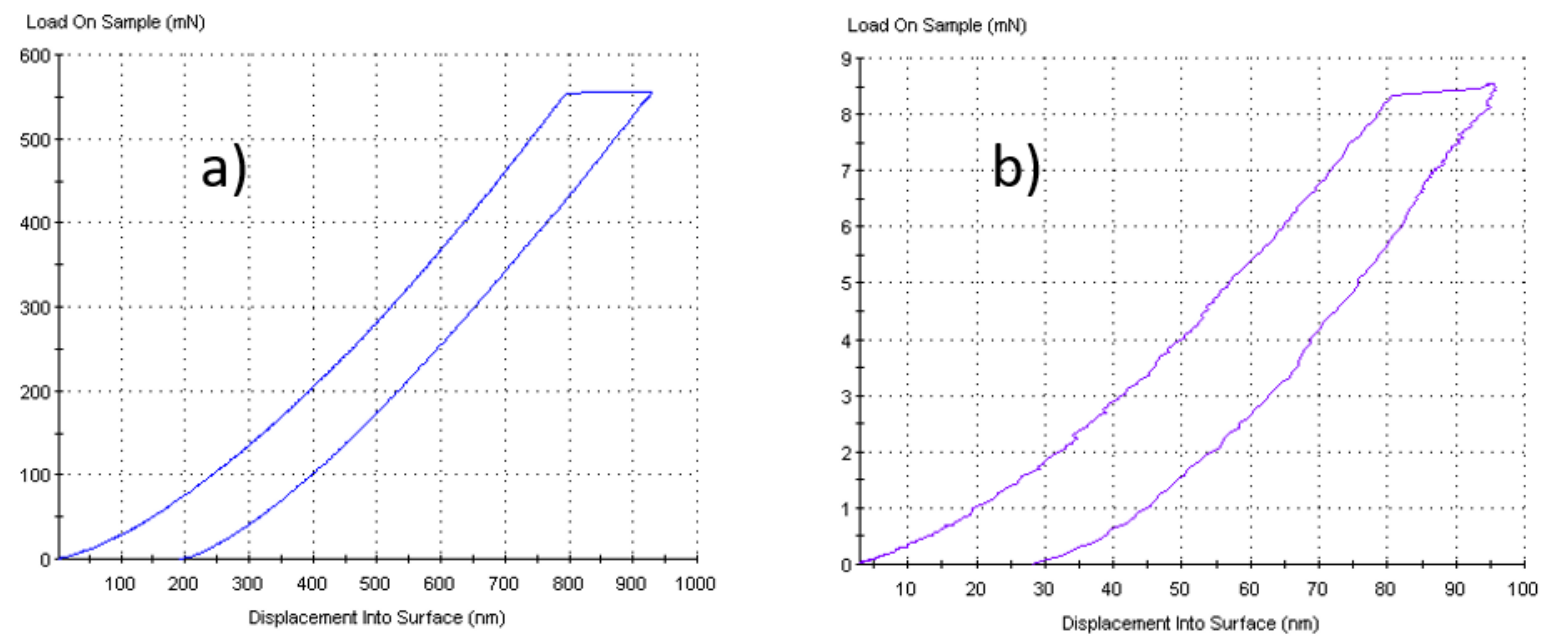

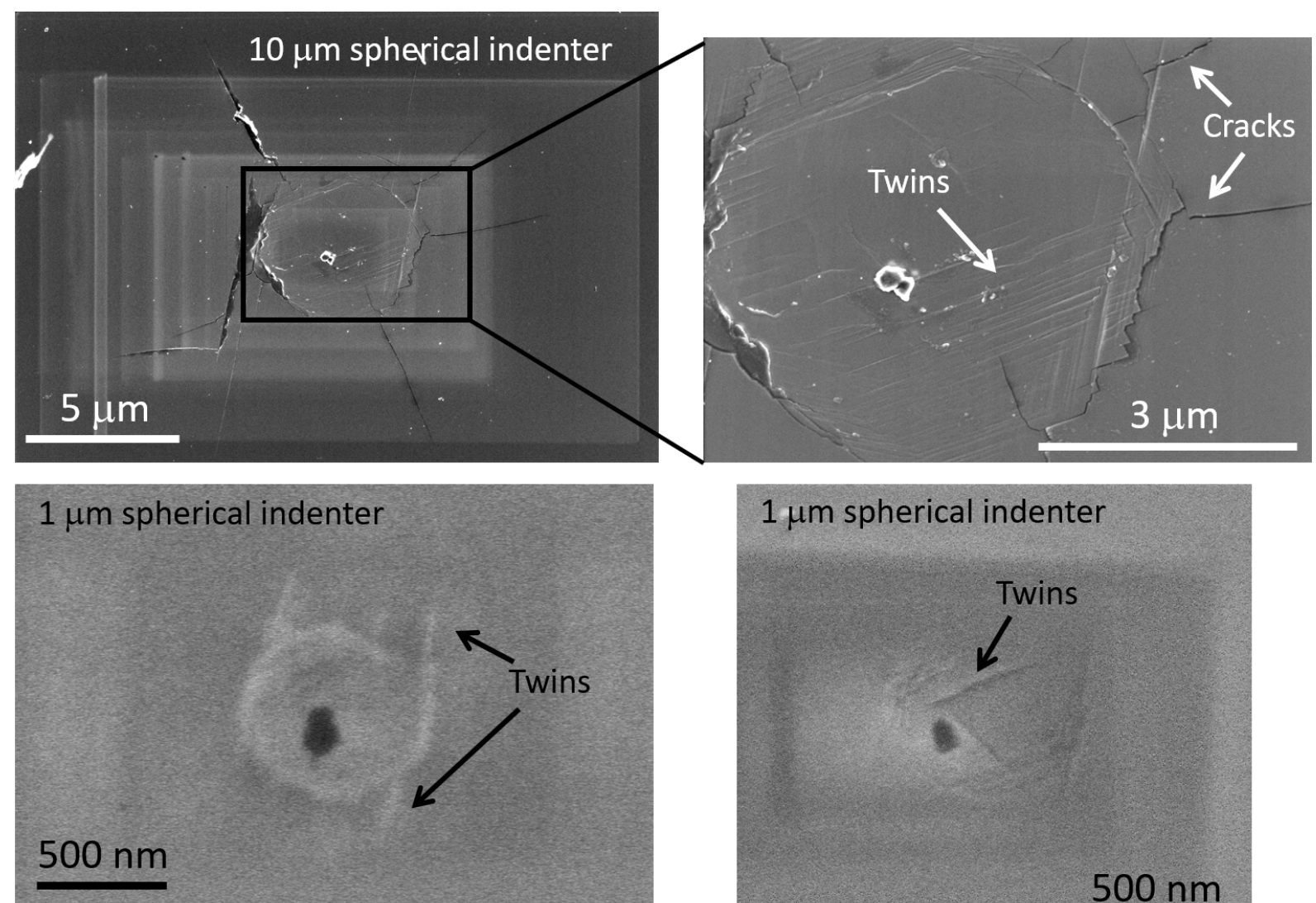

$1 \mu \mathrm{m}$ spherical indenter

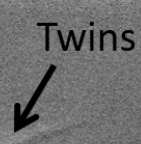




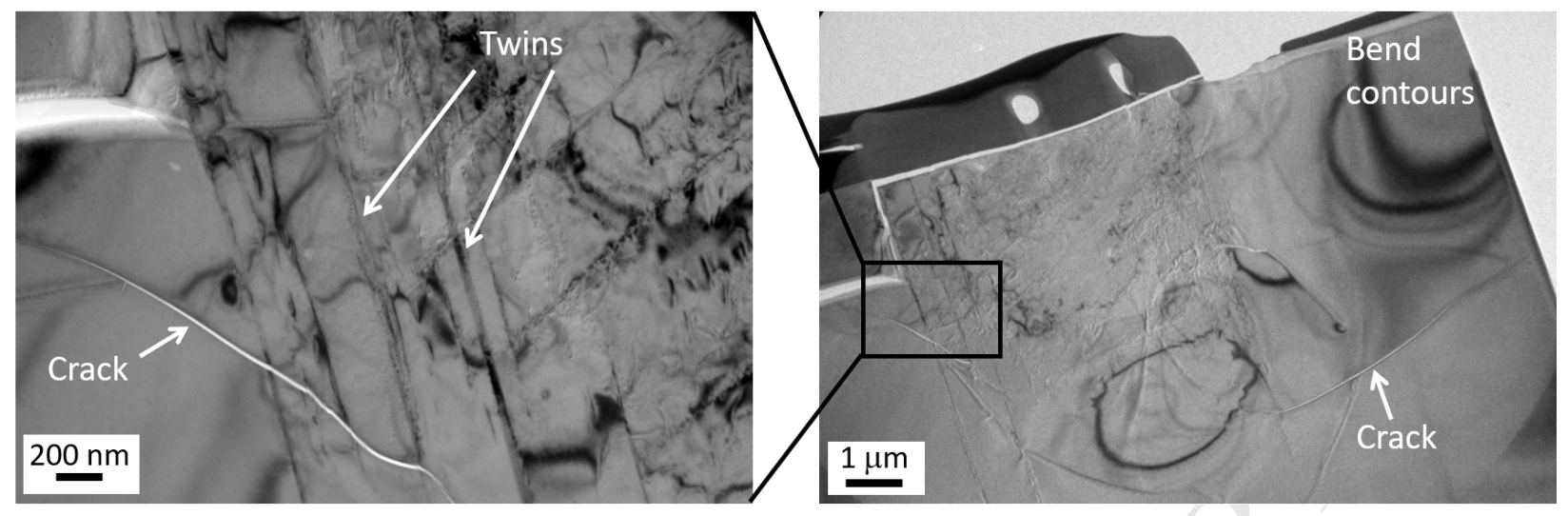



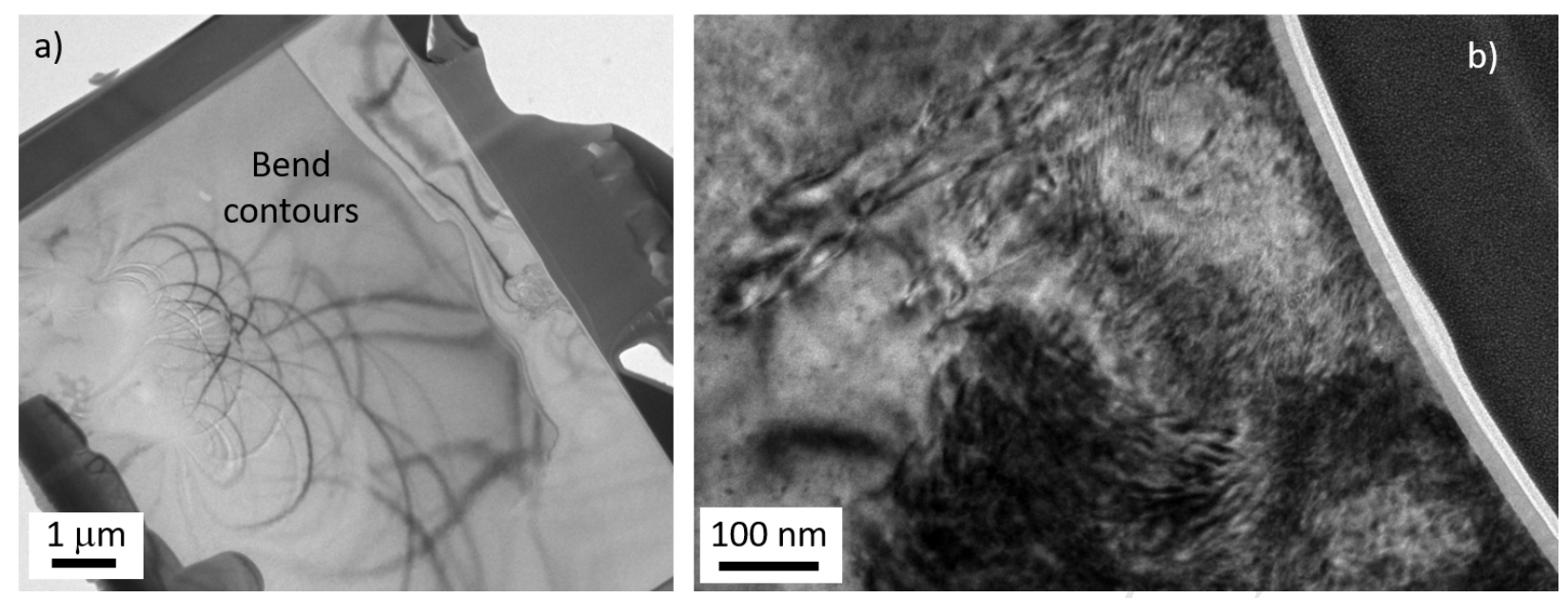

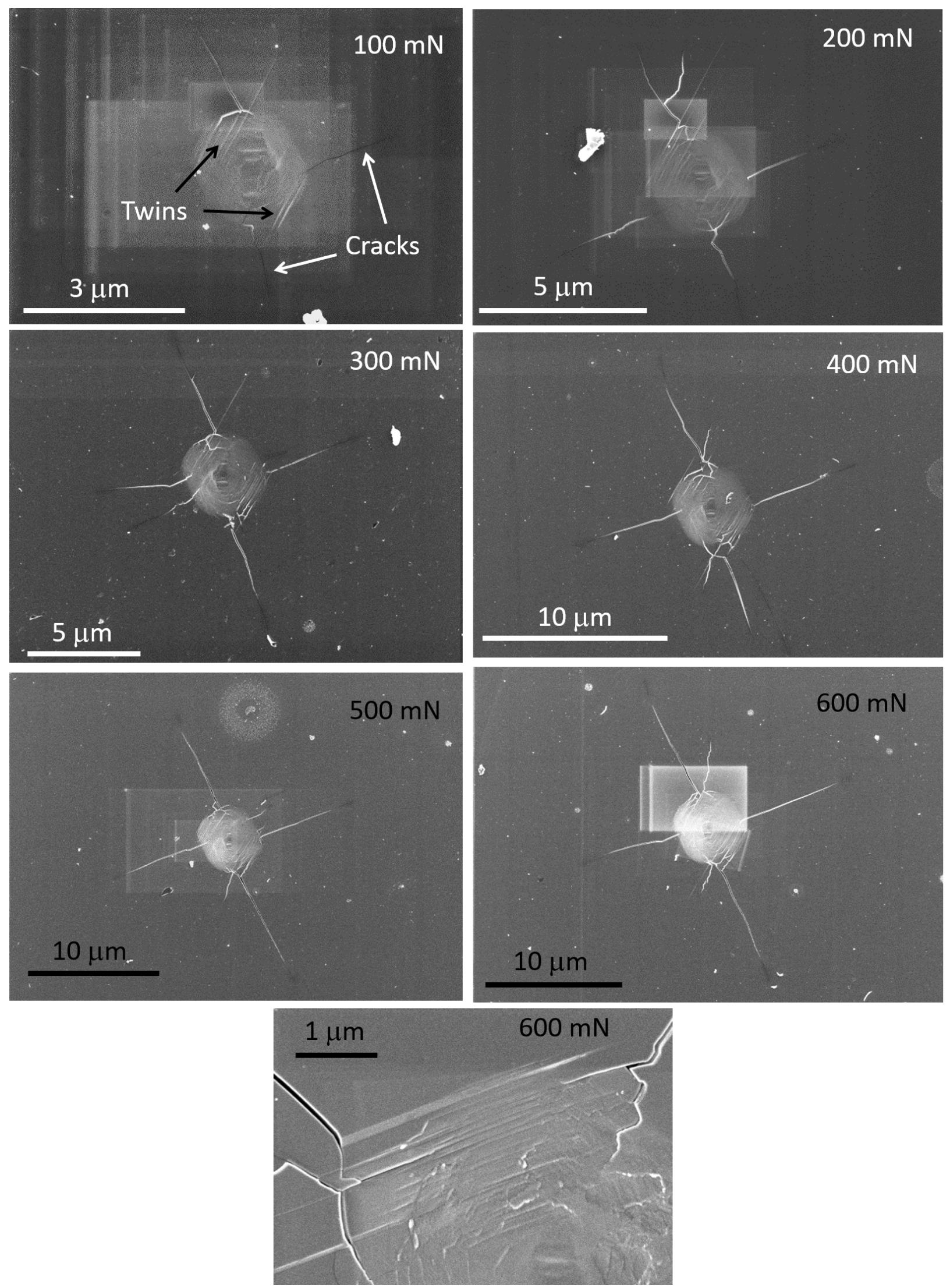


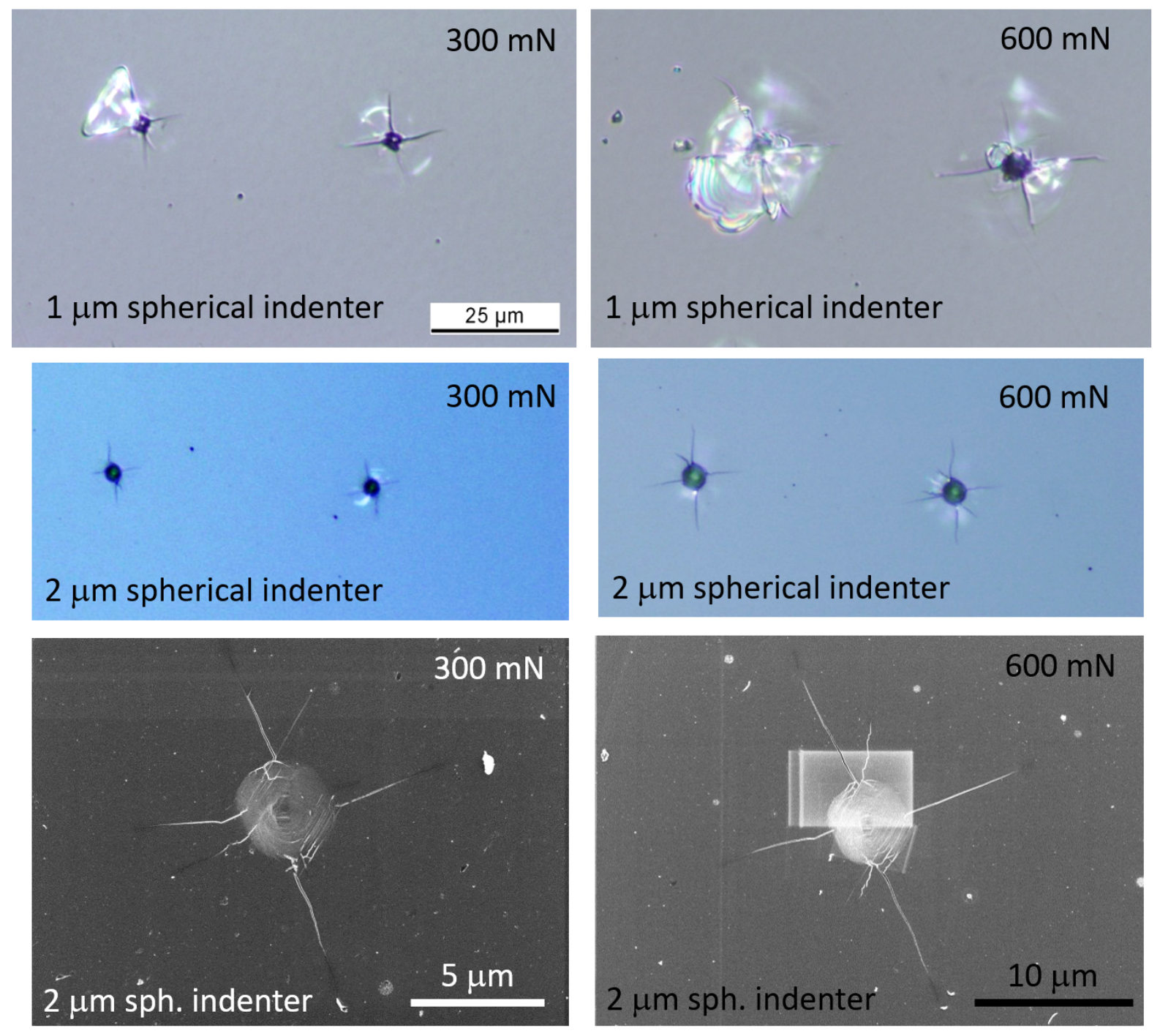

